\title{
Justiça ambiental e o caso das comu- nidades quilombolas de Oriximiná/PA: por uma crítica contemporânea da Educação Ambiental
}

Environmental Justice and the case of quilombolas communities of Oriximiná/Pa: for a contemporary critical of Environmental Education

Jacqueline Carrilho Eichenberger e Vilmar Alves Pereira. (Brasil)

\begin{abstract}
Resumo
Oartigo pretende elucidarquestões relacionadas ao pensamento ecológico contemporâneo, filosófico, antropológico e social relacionado à Justiça Ambiental, trazendo para o debate o caso das comunidades de Oriximiná/PA junto com uma profunda crítica aos paradigmas dominantes do conhecimento ambiental e da própria Educação Ambiental. A investigação aponta que a justiça ambiental, assim como, a educação ambiental se estabelecem no espaço que é do conflito, da disputa pela reapropriação da natureza e da cultura, onde natureza e cultura resistem frente à imposição de valores e processos ao se transformarem em valores de mercado. No Brasil, as "populações tradicionais" vêm sendo ao longo de décadas, deslocadas de suas terras para dar lugar a represas, projetos de mineração, agricultura em grande escala, construção civil, turismo de massa, retirada de madeira e rodovias, muitas vezes com base no paradigma da "propriedade".
\end{abstract}

\section{Astract}

The article aims to elucidate issues related to contemporary ecological, philosophical, anthropological and social thinking related to Environmental Justice, bringing to the debate the case of the communities of Oriximiná IPA, Brazil, together with a deep critique of the dominant paradigms of environmental knowledge and Education itself Environmental. The investigation points out that environmental justice, as well as environmental education are established in the space that is the conflict, the dispute for the reappropriation of nature and culture, where nature and culture resist the imposition of values and processes as they become values of the market. In Brazil, "traditional populations" have for decades been displaced from their lands to give way to dams, mining projects, large-scale agriculture, construction, mass tourism, logging and Basis of the "property" paradigm.

\section{Palavras-chave}

Justiça Ambiental; Educação Ambiental.

\section{Keywords}

Environmental Justice; Environmental education. 
Primeiras reflexões: na

busca de uma (outra) interpretação da realidade

A partir da compreensão de que as florestas tropicais, assim como a Floresta Amazônica, constituem-se como locais fundamentais para que se de, de qualquer forma, a penetração capitalista, percebe-se que as grandes empresas extratoras, mineradoras, agroindustriais, energéticas, infraestruturas portuárias- capazes de atender apenas a demanda por mercadoria, juntam-se agora as entidades relacionadas aos "recursos naturais" e a biotecnologia com o objetivo de regulamentar ou utilizar espécies vivas de maneira rentável. "Em diversas partes do mundo, grupos de habitantes locais das florestas tropicais se organizam diante dessas investidas por parte de poderosos agentes políticos e econômicos" (ESCOBAR e PARDO, 2005, p. 4).

Na região da Amazônia brasileira, estes fatos se manifestam de forma intensa já que organizações de negros (Foto 1) e indígenas, há tempos, lutam contra o governo e indústrias para obter reconhecimento legal das suas terras e das suas autoridades contra as empresas madeireiras, mineradoras e contra projetos governamentais de construção de estradas, portos, mega hidroelétricas e, mais recentemente, sobre as discussões relacionadas à comerciali- zação de espécies utilizadas tradicionalmente ou existentes nos seus territórios.

Verificamos que o controle destes territórios constitui o núcleo central das suas lutas e isto representa a afirmação do respeito pelas suas especificidades culturais, pela autonomia para decidir o seu futuro e à proteção dos seus conhecimentos tradicionais.

Para desenvolver esta luta, os movimentos dos povos das florestas e dos rios, comunidades quilombolas, índios e ribeirinhos se associam a aliados seja em nível local, nacional e internacional. Assim, os movimentos negros e indígenas têm delineado políticas culturais e ambientalistas que articulam diversos aspectos da sua estratégia de procura de bem-estar para as populações através de suas práticas milenares e do uso dos recursos naturais. "As propostas destes movimentos sociais [...] fazem parte de uma visão mais ampla sobre a sociedade e a natureza e constituem políti-

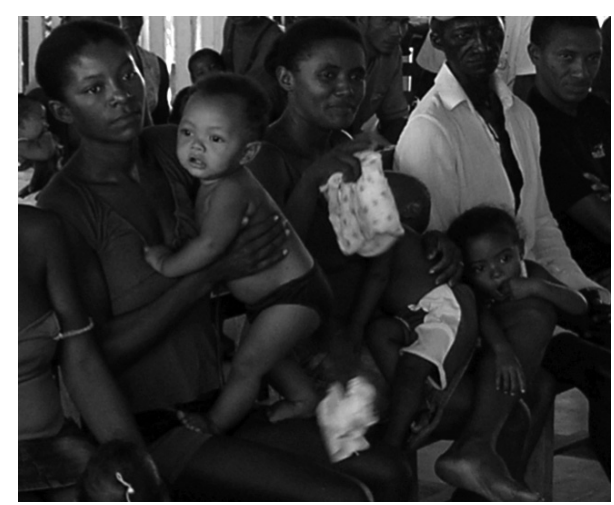

Foto 1: Reunião comunitária na comunidade do Abuí. Porto Trombetas/PA. 
cas culturais que se opõem às visões dominantes geradas pelos agentes do capital" (ESCOBAR e PARDO, 2005, p.4). Tais lutas estão para além de ações reformistas tradicionais, herança da educação ambiental conservacionista que conhecemos hoje no Brasil, e estas ações sim apresentam características de emancipação, já que consolidam direitos, formas seculares de organização, alternativas ao poder do Estado e do capital, além de atribuir a esses povos sistemas de conhecimento alternativo.

Compreendemos que, cada vez mais, o capitalismo avança com seus regimes de exploração sobre as florestas tropicais não só do planeta, mas, principalmente, em locais que ainda as mantém preservadas, como no caso do Brasil e tais regimes têm provocado "grandes danos Ecológicos sobre estes frágeis ecossistemas" (ESCOBAR e PARDO, 2005, p.5),

O discurso hegemônico tinha apresentado estes vastos territórios como inabitados e insalubres, territórios selvagens que deviam ser submetidos para dar o seu contributo à economia e aos Estados nacionais em que estão inseridos. Recentemente, porém, a abundância e a heterogeneidade das espécies da floresta tropical e a sua estrutura bioquímica, genética e molecular passaram a serem consideradas recursos valiosos sobre os quais os agentes estatais, capitalistas ou de movimentes sociais elaboram diferentes e conflituosas estratégias de aproveitamento (ESCOBAR e PARDO, 2005, p. 5).
Assim, ainda sobre o pensamento do autor, na maior parte dos casos, os moradores dessas áreas caracterizadas como zonas florestais úmidas, quilombolas, indígenas, ou mesmo ribeirinhos deslocados à força (ou por falta de opção), secularizaram métodos produtivos sustentáveis e de baixo impacto sobre o conjunto do ecossistema.

\section{Povos do rio: quilombolas de Oriximiná/PA}

Falar sobre as comunidades quilombolas de Oriximina/PA deverá nos remeter a lembranças de um passado secular, porém, ainda profundamente vivo na memória desses remanescentes de quilombos. Trata-se de uma história iniciada em meados de 1800 quando afrodescendentes refugiaram-se na região do rio Trombetas em busca de proteção e abrigo. Aqui, segundo relatos, negros africanos compartiIharam o rio, a floresta e todo o alimento oriundo dela, com os índios que aqui já estavam. Enfrentaram as fortes chuvas, as corredeiras, o sol intenso, animais selvagens e diversas doenças como a malária, a febre amarela e outras.

Porém os negros "fugitivos" não desistiram pois tal condição significava para eles a liberdade de seu povo. Após e mesmo antes do ano de 1888, quando da assinatura da Lei que libertava da escravidão os 
homens e as mulheres no Brasil, iniciou-se um movimento de coragem e também de luta pois tudo estava apenas começando para esses afrodescendentes que ainda teriam um grande desafio pela frente: enfrentar o preconceito que perduraria por anos a fio junto à sociedade escravista. Aproximadamente cem anos depois, já completamente adaptados, os negros da região do Rio Trombetas fundam a Associação dos Remanescentes de Quilombo Moradores de Oriximiná-ARQMO. De lá para cá, a entidade vem desenvolvendo ações que buscam, entre outras, a titulação de seu território já que possuem uma cultura própria com base extrativista tradicional e de sobrevivência.

Entender a importância desses grupos negros que habitam as margens do Rio Trombetas/PA, distribuídos no interior de lagos e igarapés, ligados a "furos" e "Paranans" (Foto 2), característica local desse sistema hidrográfico nos remete, sem dú-

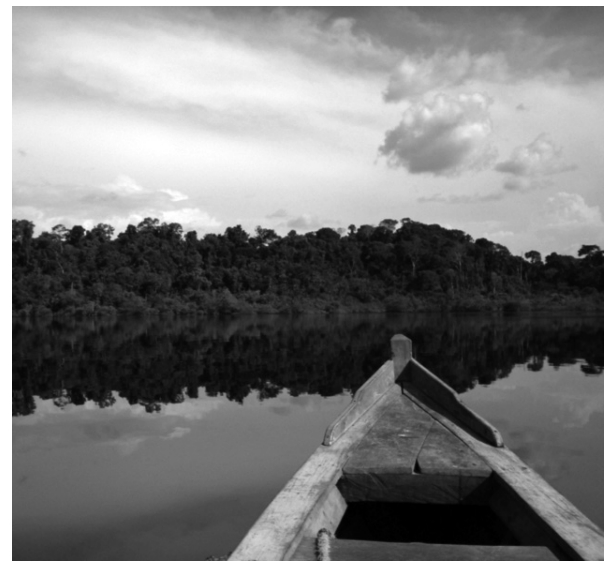

Foto 2: Detalhe de barco utilizado pelos comunitários no Rio Trombetas/PA. vida, a uma abordagem sobre os antecedentes e a tradição de ocupação por eles desenvolvida. Foi realizada uma pesquisa junto a essas comunidades que requereu uma vasta revisão bibliográfica sobre suas formas de integração e manejo, além de intervenções em campo para entrevistas e documentação fotográfica. Foram entrevistados 758 comunitários durante parte do ano de 2005 e parte do ano de 2006 totalizando um ano de expedição. Os aspectos levantados basearam-se principalmente na população existente, origem das famílias, agricultura e produtos florestais.

No que se refere à distribuição comunitária e, sobretudo, o levantamento da origem das famílias, os dados de campo indicaram que $70,6 \%$ dos entrevistados declararam-se remanescente de quilombo em relação aos $27,5 \%$ dos que se declaram ribeirinhos e dos 1,9\% dos indígenas, habitantes da região do rio Trombetas. Tal região compreende cerca de 500.000 hectares de floresta amazônica, rios, platôs, lagos e campinaranas, protegidos como áreas de proteção ambiental.

Compreende-se que na época correspondente ao ano de 1880, época em que crescia o movimento dos abolicionistas, fugiram de Óbidos, Alenquer e Santarém, localidades que mantinham fazendas com trabalho escravo. Tal resistência, que durou longos anos, explica a originalidade do mundo social que construíram nessa região. Segundo diferentes historiadores e 
antropólogos que estudam a região desde a origem de sua ocupação, há cerca de 200 anos, os quilombos localizados ao longo do rio Trombetas/PA representam o maior espaço físico conquistado e controlado por homens e mulheres que se rebelaram e fugiram da escravidão. Homens e mulheres livres e por índios destribalizados no estado do Grão Pará e posteriormente na Província. Atualmente o povo negro localizado ao longo do rio Trombetas assume a identidade política de remanescentes de quilombos autenticada pela presença de mais de três gerações em quase dois séculos neste território. $A$ condição de etnia, conforme AcEvedo e CASTRO (1998) é traduzida pelo reconhecimento de uma origem comum e de formas de coesão, marcas da singularidade dessa ocupação. Em constante construção com base na tradição a memória social oscila entre o hoje e o ontem e se mantêm viva a cada dia por força de sua luta, resistência, liberdade, territorialidade e etnia.

Observou-se que os mesmos se encontram estruturados em um complexo sistema de organização social em torno de práticas econômicas e culturais que lhes são particulares. No que se refere à agricultura, os dados apontaram que $70,6 \%$ dos entrevistados realizam agricultura de subsistência (Foto 3 ) onde 28,3\% comercializa o excedente na feira de Oriximiná e Porto Trombetas-pequenos núcleos urbanos da região. Outra fonte de renda declarada pelos entrevistados refere-se ao extrativismo de produtos florestais não madeireiros, principalmente a castanha (69,68\%), o açaí $(16,25 \%)$, a copaíba $(21,26 \%)$, os cipós $(7,83 \%)$, o breu $(11,31)$, o ubim $(3,84 \%)$ e a andiroba (1,05\%). Tais características- únicas, leva-os a reconhecerem-se como "Filhos do Rio" cujos antepassados encontraram no Rio Trombetas/ $\mathrm{PA}$, condições naturais favoráveis a uma existência livre em oposição à situação de escravidão na qual se encontravam.

Sobre a escravidão, a maioria prefere não falar sobre o assunto, porém é a partir de sua denominação como mocambeiros - termo utilizado no século XIX por governadores e corpos de policiamento para identificar o agrupamento de escravos fugitivos, impregnado de conotações negativas, que suas vidas passam a fazer sentido. Mocambeiros ou mocambistas eram tidos como criminosos desertores e preguiçosos pela sociedade escravista e, infelizmente, após séculos de história contada, muitos ainda insistem nessas conotações.

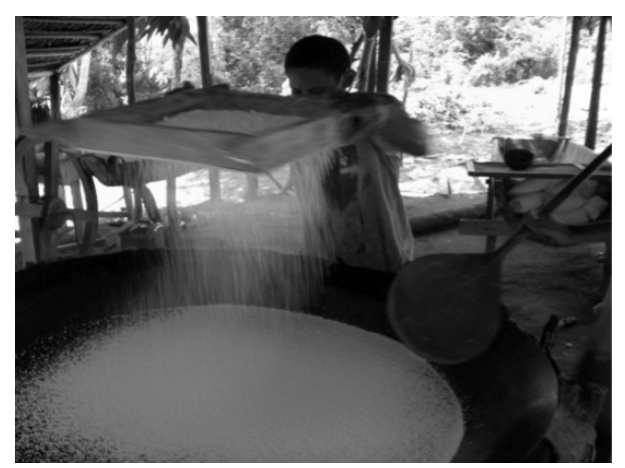

Foto 3: Processo comunitário de fabricação de farinha na comunidade Mãe Cué. Trombetas/PA. 
O processo de titulação de Terras quilombolas só recentemente foi regulamentado pelo Decreto Federal $n^{\circ} 4.887$, de 20 de novembro de 2003. As terras de quilombo têm sido regularizadas através de título coletivo outorgados em nome da associação de comunidades. A ocupação da terra se dá por meio do sistema de uso comum -base física comum, essencial e inalienável, incluindo laços de solidariedade e ajuda mútua. $O$ indivíduo e sua família não são considerados donos da terra, seu direito a propriedade limita-se apenas ao resultado do trabalho por eles apreendido.

Os quilombos possuem, portanto, uma interpretação jurídica. Ao apoderarem-se do potencial da floresta e das águas, esses "Povos do Rio" construíram, dia após dia, suas raízes étnicas associadas à noção de território. Para eles, viver, apropriar-se e transformar a natureza encerra atos criadores de existência material e social. As formas sociais percebidas sintetizam dados materiais (rio, peixe, barco, árvore) e abstratos como os projetados por imagens místicas, sensibilidade, desejos e afetos em espaço contínuo, não fragmentado.

Outras formas de apreensão do ambiente onde vivem são para esses remanescentes, estranhas a sua realidade construída caracterizando-se como rupturas em seus significados -reais ou imaginários. A noção de território, como se pode observar, é um resumo da utilização e apropriação desse mundo- práticas desenvolvidas dia a dia na busca de estratégias de vida e de trabalho. Assim como, o manejo dos recursos naturais por meio de "técnicas rudimentares" desenvolvidas por seus antepassados os sustenta ao longo de gerações em uma extensão de terra "não calculada" até hoje, além de ser responsável pela construção da representação de seu território.

Desde os Mocambos, termo utilizado no século XIX até os dias atuais, com a caracterização do termo "Comunidades tradicionais", o caminho percorrido pelos povos negros dessa região esteve relacionado à conquista de justiça e igualdade de direitos: $O$ direito sobre a terra historicamente conquistada. $O$ direito sobre a sua especificidade negra, raiz profunda de sua cultura. O direito de reproduzir seu modo de vida agrícola e extrativo sobre as bases de territorialidade concedida com manejo ecológico traduzido pela preservação, atestado nos duzentos anos de existência no Lugar.

\section{Prática de resistência: à formação de quilombos}

A revolta diante da condição do regime escravista da época promoveu as diversas fugas de escravos às vezes de forma individual ora de forma coletiva, ainda no inicio do século XIX, conforme os diversos 
registros encontrados nas diferentes bibliografias pesquisadas. Observou-se que o processo de fuga - relacionado à prática de resistência, geralmente ocorria em épocas de festas e no período de cheias compreendido entre os meses de dezembro a maio. Nessa região esse período coincide com o inverno e com a temporada da castanha.

Observa-se pelos registros que encontrar os irmãos, assim como, um lugar que propiciasse alimento e proteção eram objetivos dos escravos foragidos que buscavam o Trombetas. O processo de fuga se inicia com a subida de escravos fugitivos as cachoeiras ou isolando-se em lagos menos transitáveis. Lá formavam os quilombos ou mocambos. As fugas de escravos para os quilombos, pelo que se observa, passaram a se tornar a forma mais expressiva de rebeldia e contestação frente à sociedade escravista.

A partir daí, a criação de um mundo livre, independente, livre de licenças e de permissões, à custa de um "exílio", um isolamento assegurado por longos deslocamentos, rio acima, que os afastariam das ameaças e das perseguições. Os senhores passaram a elaborar medidas de controle, perseguição e prevenção de novas fugas. Podemos citar os atos e resoluções aprovados pelas Câmaras prescrevendo a organização de milícias, como também a série de normas e punições ditadas para os não negros e para os homens e mulheres livres que passavam a relacionar-se com os chamados mocambeiros. Nesta ocasião, entra em cena, a figura dos regatões - pequenos comerciantes que passaram a subir o rio para a prática de trocas de mercadorias junto aos foragidos, que também passam a ser coagidos. O objetivo principal de tais medidas foi o de coibir a ameaça que o comportamento revolucionário dos negros representava para a o sistema escravista que insistia em se impor.

\section{Século XX: \\ outra abordagem na disputa por territórios}

Historiadores ao longo dos séculos referem-se que a existência desses quilombos por tanto tempo demandava a existência de uma estrutura de poder e liderança apta a sustentar a unidade, coordenar as ações de resistência e garantir a reprodução dessas sociedades. Segundo AcEveDO e CASTRO (1998), a dinâmica interna de fortalecimento desses grupamentos estava condicionada a capacidade de reprodução. Porém, por meio das relações de espaço, cria-se uma unidade onde o quilombo representa a condição e existência do escravo aquilombado e o espaço físico somente define-se como tal por essa presença.

O movimento quilombola no rio Trombetas representou a construção de estratégias 
para uma existência social estável, com princípios econômicos, social e político. Tal existência social Ihes permitiu o enfrentamento como coletividade diferente e até necessária para a sociedade escravista, já que esses negros em seguida passam a se relacionar comercialmente com Óbidos onde os quilombos passaram a registrar índices significativos na economia regional. Nesse caminhar construíram sua identidade étnica definida e continuamente recriada, baseada em um conjunto de práticas e de padrões regulares de comportamento transmitidos na socialização de concepções, de valores éticos e de princípios comuns, constituindo-se como elemento unificador e articulador.

A bagagem cultural-simbólica dessas comunidades negras, como visto em diferentes registros, é atribuído a esse ir e vir, a essa contínua movimentação nas cachoeiras, impelidos pela necessidade de fuga. Tal período é caracterizado por um período de gestação social. Observou-se, durante as pesquisas sobre domínio territorial no Trombetas em bibliografia disponível, que poucos negros são identificados nos documentos legais como registros de posses, títulos de propriedades, escrituras de arrendamento. Os usuários e moradores do Alto e Médio Trombetas passaram a figurar nos livros cartoriais somente como uma referencia quase invisível. Observou-se pelos registros que a caracterização "Terras de pretos" permitia as vezes que os mesmos saíssem do anonimato, so- mente referindo-se a limites de terras transacionadas.

Observa-se que a razão desse povo negro não se relacionava pelo título de propriedade privada e sim por relações de trabaIho coletivo (Foto 4).

Os negros do Trombetas permanecem até hoje sob um sistema que privilegia o desenvolvimento comum de atividades (moradia e sobrevivência) sobre um território continuo adequado à coleta, roças e quintais.

Consta que no início do século $\mathrm{XX}$, Raimundo DA COSTA LIMA conhecido como Coronel Costa Lima ampliou seu domínio de terras na boca do Lago Jacaré. Como constam, seus herdeiros negociaram essas terras em 1980 com a empresa Rio Xingu S/A cujo proprietário era o húngaro Kalman SomOdy, responsável futuramente pela expulsão de muitos negros daquela região. Observa-se ainda que o historiador Vicente Salles segundo AceVEdo e

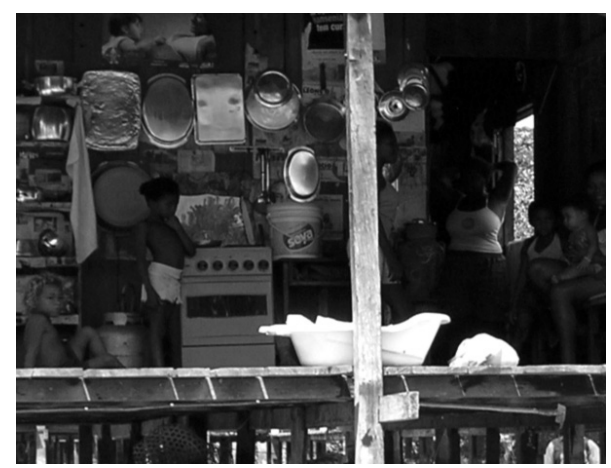

Foto 4: Moradia característica na comunidade de Juquiri. 
CASTRO (1998) escreve os primeiros artigos denunciando à problemática, mais uma vez, enfrentadas pelos negros em relação ao contraditório processo de titulação de terras que ameaçava sua existência nesse território. Segundo o historiador:

[...] enquanto os negros lavraram a terra, para nutrir a economia de Óbidos, do Estado, do Pais [...] alguém que não traças e cupins lavravam termos em cartórios. E a posse é garantida pelos papéis. Não pelo trabalho. Esses papéis sustentam a voracidade das traças e do cupim (ACEVEDO e CASTRO, 1998, p. 138).

Essas comunidades integram-se em uma teia de relações construídas ao longo de sua história e intensa bagagem simbólica, agregada a memória dos mocambos garantindo seu direito de permanecer nas terras conquistadas em tempo presente junto aos novos desafios que ainda enfrentam. Do ponto de vista político, essas comunidades espalda em sua história, organizando-se em associação de luta de direitos na demarcação definitiva de seu território, legitimada pela Constituição Federal.

Conforme os estudos encontrados a propriedade privada aparece como um valor do branco, ausente ao pensamento negro quilombola -este, com base na sobrevivência e reprodução, manteve uma hierarquia de equidade tendo como elo de integração os valores básicos de cooperação e reciprocidade. Nestas teias de relações, núcleos familiares negros mantêm uma profunda relação de união como chave de subsistência enquanto o grupo valoriza a terra como único meio de vida. Observa-se a dificuldade em nossa cultura de se entender os limites do território de uso comum que de forma interrompida interagem comunidades em uma mesma área.

Segundo Acevedo e Castro (1998), das intervenções recentes nesta região destaca-se pela importância do impacto gerado e do qual, inevitavelmente, muitos outros decorrem, a presença de um violento processo de usurpação das terras de uso comum dos negros com a chegada de comerciantes, empresas e órgãos públicos e consequentemente, o acirramento da competição pelos recursos a partir da segunda metade do século XX. O encontro realiza-se entre duas ordens, duas racionalidades - empresarial e agro extrativa com concepções sobre usos e propriedade da terra (e de seus recursos) bastante contraditória. Antigos comerciantes e patrões que se utilizam do prestígio pessoal, do paternalismo e do trânsito político para apropriaram-se dos castanhais, com títulos definitivos ou de arrendamento.

\section{Por uma crítica contemporâ- nea da educação ambiental}

Na busca de uma crítica contemporânea para a Educação Ambiental, a Ecologia Política nos traz interessantes pontos para 
reflexão e ainda a possibilidade de reflexão sobre a própria reflexão, ou seja, a possibilidade de rever o pensamento que move a cultura humana nos últimos séculos e que conduz a humanidade por toda a modernidade e nos constituiu até desembocar em uma espécie de beco sem saída no que trata das questões ambientais.

Atualmente vivemos uma crise civilizatória e planetária, surge diante do pensamento contemporâneo à necessidade de reflexão sobre esse fenômeno chamado Modernidade -que parece sempre conduziu a ascensão capitalista, científica e tecnológica ou, até mesmo, sobre uma suposta/necessária pós-modernidade, a saber, uma Hipermodernidade onde, segundo LIPOVETSKY (2004), o pós se firmou apenas como transição. Tratamos modernidade como uma característica daquilo que é "moderno", que transcende o obscurantismo, quem sabe, um espírito crítico, ideias de progresso de renovação, liberdade, ciência e cultura e esses valores precisam ser revistos, pois a muito já foram desacoplados de nosso cotidiano.

Podemos citar LyOTARD (2009) com a ideia da necessidade de uma condição pós-moderna, de superação da modernidade onde a emancipação deve ser alcançada por meio dos sentimentos, da arte e da criação, ou, podemos ainda citar HABERMAS (2010) que insiste em um projeto de modernidade inacabado que precisa ser levado adiante, cuja emancipação do ser humano, da ideologia e da dominação político-econômica só será possível por meio da filosofia da linguagem. De qualquer forma, acentuam-se os argumentos de que já estamos no limiar de uma nova era e que este está nos levando para além da própria modernidade e pós-modernidade. Para GIDDENs (1991) parece que nos deslocamos para um sistema relacionado mais centralmente com a informação. Além disso, o autor explica que tais controvérsias enfocam amplamente questões de filosofia e epistemologia.

Estamos alcançando um período em que as "consequências da modernidade estão se tornando mais radicalizadas e universalizadas do que antes". Além da modernidade, devo argumentar, podemos perceber os contornos de uma ordem nova e diferente, que é "pós-moderna"; mas isto é bem diferente do que é atualmente chamado por muitos de "pós-modernidade". (GIDDENS, 1991 p. 52).

Observa-se que, com base em sua compreensão fenomenológica da modernidade, sem deixar ainda de lançar uma profunda crítica ao pensamento dominante principalmente junto aos estudos da vida social moderna, GIDDENS (1991) questiona as instituições modernas capitalistas e industriais na modernidade. Para o autor o capitalismo pode ser compreendido como um sistema de produção de mercadorias, centrado sobre a relação entre a propriedade privada do capital e do 
trabalho assalariado em relação com um sistema de classes que depende do ciclo produtivo-produtores e consumidores. Neste sentido, o industrialismo encontra-se relacionado à utilização de energia material na produção de bens e na utilização das máquinas - artefato movido a fontes de energia capazes de realizarem tarefas onde certamente alcançaram em pleno século XXI status de alta tecnologia aplicados aos transportes, às comunicações e a vida cotidiana.

Orquestrados pela competição e expansão do próprio projeto capitalista, o autor sugere que a "inovação tecnológica tende a ser constante e difusa" (GIDDENS, 1991, p. 55). Alienada do contexto social, a economia se fundamenta sobre a propriedade privada dos meios de produção. Dessa forma, no sentido Heideggeriano, a globalização intensifica as relações sociais, interliga localidades distantes a acontecimentos locais que em um processo dialético se modelam e se transformam. Assim, "vemos o fortalecimento de pressões sobre a autonomia local e identidade cultural regional" (GIDDENS, 1991, p. 62). O autor compreende que a tecnologia moderna prevê alterar substancialmente as relações pré-existentes entre a organização social humana e o meio ambiente. Junto a esta tecnologia, o uso de fertilizantes, a mineração, a imposição de hidrelétricas, entre outras, como no caso das comunidades quilombolas de Oriximiná.
Assim, é preciso indagar e compreender uma racionalidade não instrumental, em relação à dominação econômica, técnica e científica da natureza no pensar a Educação Ambiental? O breve histórico do progresso mantém uma relação com a exploração do ser humano e da natureza por ele próprio. O modelo capitalista começa a mostrar-se insuficiente para o desenvolvimento biológico social, cultural e econômico. Paralelamente a esta compreensão, observa-se que as questões ambientais são intrínsecas às questões sociais, à pobreza, à escassez de recursos e à expansão populacional e combina-se para a degradação e o colapso dos ecossistemas urbanos e sociais a nossa volta. Diante disso, prevalece uma Educação Ambiental marcada pela tradição explicativa das ciências naturais.

Vale considerar que Educação Ambiental, antes de tudo é Educação e parte das ciências das humanidades, mas a concepção tecnológica que têm da interpretação, com a sua "metafísica realística", promove a própria irrelevância quando não consegue dar conta dos problemas ambientais contemporâneos. Podemos compreender que a "epistemologia cientifica", como já mencionou Maurice Merleau-Ponty em PALMer (1969), como objetivadora e manipuladora das coisas, acabam por desistir de ser parte nelas. Ao refletir sobre realismo e a perspectiva científica as ciências humanas acaba por adotar um modo científico de pensar. De caráter objetivo, ope- 
ratório e estático, o pensamento sobre as ciências humanas carece de significado e transmitem no que se refere às ciências sociais, uma ausência de sentido, histórico, cultural.

Como atividade politica-pedagógica a crítica social veio consolidar a Educação Ambiental como campo de conhecimento, como um campo plural, histórico, social e exige o questionamento dos problemas ambientais, de sua gênese, contradições, consequências e de suas possíveis alternativas ainda subordinada à ecologia científica, que nos mostra os efeitos de nosso comportamento e práticas e amplia a "análise" por ampliar a definição do objeto quando o contextualiza em sua realidade histórica e social. Porem, ainda mantemos a imagem científica (biológica) do objeto, do ser. Ao estudar Palmer, observa-se a emergência de uma teoria, um método de transformação capaz de decifrar a matéria humana naquilo que estamos voltados a interpretar, ou seja, o ser do objeto. Isso nos leva a concordar com PALMER (1969, p. 19) "que as ciências humanas precisam de uma Hermenêutica para compreendê-las", ou seja, de uma interpretação adequada que, pelo menos acompanhe os métodos de análise científica, sem tornar os objetos das ciências humanas -lutas, obras, textos, imagens, "silenciosos e naturais".

Tal compreensão possibilita aprofundar modos de compreensão relacionados a conteúdos históricos e humanísticos. A in- terpretação sobre o conhecimento histórico e humanístico deixa de ser um conjunto de artifícios e técnicas de "explicação do conhecimento" sobre o conteúdo de Educação Ambiental, mas uma reflexão sobre a própria interpretação. A busca por uma nova compreensão do universo fez ressurgir a ciência natural, a ciência da natureza. Esse novo enfoque caminhou rápido, libertando o ser humano de pressupostos metafísicos dogmáticos e de uma forma de conhecimento com resultados pouco práticos e eficazes. Porém, ao considerar que o ser humano encontra-se cada vez mais distanciado e desvinculado da natureza, acabando por desconsiderar a importância das atitudes e do efeito de suas ações sobre o mesmo, é possível observar a crescente degradação ambiental e o agravamento dos problemas sociais resultantes.

Sendo assim, é possível considerar também que o surgimento da Educação Ambiental como prática para a liberdade, constitui-se como terreno fértil para uma pedagogia crítica que busca uma espécie de revolução do pensamento. A necessidade de repensar o ser e a complexidade como uma proposta de reconstrução do mundo e de reapropriação social da natureza, para além da globalização que unifica os olhares, pode ser uma alternativa para recompor um mundo alienado e fragmentado, herdado dessa civilização em crise. 
Segundo o documento de consulta pública do Plano Nacional de Áreas Protegidas PNAP, instituído por Decreto Federal 5.758 de 13 de abril de 2006, no desenho do sistema de áreas protegidas deve contemplar a diversidade ecossistêmica, étnica e sociocultural associada a esses ambientes. As potencialidades de uso sustentável dessas áreas devem ser desenvolvidas e fortalecidas, visando o acesso e a repartição de benefícios que podem e devem ser gerados pelas áreas. Faz-se necessário a integração e o fortalecimento dos esforços e as práticas culturais de conservação quando, no caso, em conflito com territórios quilombolas e também ações relacionadas à participação dessas comunidades na gestão das unidades de conservação com relação ao estabelecimento de sistemas de governança e repartição equitativa dos custos e benefícios.

Cabe ao governo definir e acordar critérios para identificar as áreas de sobreposição e propor estratégia de solução para os conflitos, garantindo o consentimento prévio e informado, assim como, mecanismos de regulação junto às comunidades locais, considerando suas práticas, conhecimentos e formas de organização locais, traduz-se, sem dúvida alguma, em uma importante evolução do pensamento sobre unidades de conservação no Brasil. Acredita-se que estabelecer sistemas de governança, diversificados, transparentes, democráticos e eficazes abre-se caminho a novas formas de gestão participativa que possam contribuir particularmente para a participação de povos indígenas, comunidades locais e quilombolas e de outros setores tradicionalmente excluídos da gestão em unidades de conservação. Ocorre que as "comunidades tradicionais" são frequentemente as últimas a obterem oportunidades de desenvolvimento ou serviços sociais e ainda, a serem efetivamente envolvidas nos processos de tomada de decisão que afetam os recursos naturais.

\section{"Ecologia da diferença"}

Arturo Escobar (2011) em seu livro Ecologia Política de la globalidad y la diferencia faz uma abordagem sobre diferentes aspectos sociais, culturais e biológicos da vida atual, que se encontram estreitamente inter-relacionados. Sua preocupação com a questão de temas sobre o lugar - territórios, assim como, expressões regionais e articulações no contexto da globalização dialogam, por outro lado, com a dinâmica complexidade do capital e da cultura. Escobar (2011) irá tratar das comunidades quilombolas do médio amazonas no Brasil como culturalmente diversos que lutam por respeito a suas diferenças quando da coordenação e defesa de seus territórios, quando dos conhecimentos tradicionais como fundamentais em relações com a natureza e com sua identidade. Para EsCOBAR (2011), os ativistas indígenas e ne- 
gros daquela região não só produzem seu próprio conhecimento como também tal conhecimento constrói esquemas sofisticados, que são efetivamente parte do movimento de luta.

Funda-se então uma Ecologia política da diferença a partir do lugar, devido às mobilizações relacionadas a lutas sobre a cultura, o território, os movimentos de indígenas e negros que têm como objetivo lutar pelo controle de seu território, além disso, o lugar na opinião do autor continua sendo uma importante fonte de cultura e identidade. Da mesma forma acontece no Brasil, com as comunidades de Oriximiná/PA.

Escobar (2011) salienta o impacto da ciência e da tecnologia moderna e de sua contribuição para a destruição do meio em que se vive e ainda a sua falta de perspectivas no que se refere a soluções viáveis e eficientes na resolução dos problemas e assim: a denúncia da colonização que precisa ser revelada. Históricamente sabemos que os grupos negros representam "un modelo local de naturaleza” (ESCOBAR, 2011 p.70).

Esta gramática, integrada en rituales, lenguajes y formas de clasificación de los seres naturales, que los modernos podrían ver como extrañas, constituye las bases de la ecología cultural con la que ellos utilizan y cultivan la selva (los bosques). Estos "sistemas de producción tradicional" como han sido llamados por los activistas y expertos de La biodiversidad a media- dos de la década del noventa- han tenido una noción intrínseca de la sostenibilidad, la misma que en las últimas décadas se ha vuelto impracticable debido a una variedad de presiones (ESCOBAR, 2011, p. 70).

Trata-se de uma proposta de uma ecologia política da diferença, ou uma espécie de política prática onde, segundo o autor, integra diversas economias, ambientes e culturas, que responde ao momento atual, principalmente na America Latina, como também, uma crítica a argumentos eurocêntricos sobre a universalização da modernidade da globalização. Enfim, a ideia de que os movimentos sociais possam ser vistos como produtores de conhecimento. Esta perspectiva tem varias dimensões já que podemos refletir sobre o conhecimento e a resistência; o conhecimento como ferramenta de luta. De fundamental importância esta a identificação do conhecimento produzido por estes ativistas.

A partir da luta pelo movimento de Justiça Ambiental, foi possível, o questionamento e a discussão sobre as ligações entre problemas ambientais e desigualdade social, com preocupação de introduzir variáveis sociais nos "tradicionais estudos de avaliação de impacto". Surge a pesquisa participativa envolvendo todos os atores como coprodutores do conhecimento, na construção de políticas públicas ambientais. AcselRAD (2000) entende que se trata da construção de uma resistência global frente à dimensão global da poluição. Se, por 
um lado, sabe-se que os mecanismos de mercado trabalham no sentido da produção da desigualdade ambiental, por outro lado, observa-se a omissão das políticas públicas favorecendo a ação perversa do mercado. "A experiência do Movimento de Justiça Ambiental procurou assim organizar as populações para exigir políticas públicas capazes de impedir que, também no meio ambiente, vigorem os determinantes da desigualdade social e racial" (ACSELRAD, 2000, p.7-12).

O grande desafio se reverte em uma nova visão sobre Unidades de Conservação Brasileiras que garanta a proteção ambiental e cultural. Observa-se que existem instrumentos para se caminhar em direção a uma solução no sentido de se implementar ações eficientes.

As questões ambientais exigem um repensar e um agir diferente do que estávamos acostumados, portanto cremos que os instrumentos de gestão devem privilegiar a mudança de comportamento, através de informações, participação e desenvolvimento de ações de caráter educativo de forma continuada ao invés de sua ênfase em comando e controle.

\section{Argumentações finais}

Observa-se que as "populações tradicionais" no Brasil vêm sendo ao longo de dé- cadas, deslocadas de suas terras para dar lugar a represas, projetos de mineração, agricultura em grande escala, construção civil, turismo de massa, retirada de madeira e rodovias, muitas vezes com base no paradigma da "propriedade". Populações como a dos quilombolas de Oriximiná, caracterizadas como "Filhos do Rio" possuem um jeito singular de compreender a terra. Sabemos ainda que as áreas protegidas possuem grande potencial na sustentação dessa teoria e sua proteção pode estar relacionada ao reconhecer direitos de subsistência a essas comunidades verdadeiros donos das terras e guardiões da natureza. Seguindo o pensamento de Vandana SHIVA (2006) a degradação da natureza e o empobrecimento das tribos nos dias de hoje encontram-se intrinsecamente relacionados com a apropriação desta riqueza pelo poder externo, comercial.

No Brasil, as visões sobre o papel das áreas naturais protegidas ao longo de sua criação sempre foram questionadas. Estimava-se que somente $26 \%$ das Reservas Biológicas brasileiras são ocupadas por populações humanas e, em muitos casos, especialmente na Amazônia, essas populações habitam a região durante longos períodos que variam de décadas até séculos. Essas populações tradicionais que habitam a região do médio Rio Trombetas são caracterizadas pela prática de atividades de relativo baixo impacto ambiental (agricultura itinerante em pequena escala, colheita de produtos florestais não ma- 
deireiros, caça e pesca de subsistência). Garantir a participação dos povos no processo de gestão de seus territórios, considerando suas práticas, conhecimentos e formas de organização locais traduzem-se, sem dúvida alguma, em uma importante evolução do pensamento ambiental no Brasil. Para além de uma educação ambiental burguesa e de suas "contradições vulgares" que interferem no campo, uma educação de direitos, de justiça ambiental.

\section{Referências bibliográficas}

ACEVEDO, Rosa; CASTRO, Edna. (1998): Negros do Trombetas: Guardiões de Matas e Rios. 2. ed. Belém, Cejup/UFPA/NAEA.

ACEVEDO, Rosa Elisabeth. (1990): Estudos de Comunidades Negras no Município de Oriximiná. Belém/PA: Núcleo de Estudos Amazônicos. ACSELRAD, Henry. (2000): Justiça Ambiental novas articulações entre meio ambiente e democracia, in IBASE/CUT-RJ/IPPUR-UFRJ, Movimento Sindical e Defesa do Meio Ambiente - o debate internacional, série Sindicalismo e Justiça Ambiental vol.3, RJ, 2000, p.7-12.

BRASIL. (2003): Decreto $n^{\circ} 4.887$ de 20 de novembro de 2003. Regulamenta o procedimento para identificação, reconhecimento, delimitação e demarcação das terras ocupadas por remanescentes das comunidades dos quilombos. Brasília, DF: Diário Oficial da União.
BRASIL. (2006): Decreto $n^{\circ} 5.758$ de 13 de abril de 2006. Institui o Plano Estratégico Nacional de Áreas Protegidas - PNAP. Brasília, DF: Diário Oficial da União.

ESCOBAR, Arturo. (2011). Ecología Política de la globalidad y la diferencia. In: ALIMONDA Héctor. La Naturaleza colonizada Ecología política y minería en América Latina. Buenos Aires: CLACSO.

ESCOBAR, Arturo; PARDO, Mauricio. (2005) Movimentos Sociais e Bio Diversidade no pacífico Colombiano. In Santos, Boaventura. Semear outras Soluções: Os caminhos da biodiversidade e dos conhecimentos rivais. Rio: Civilização Brasileira.

GIDDENS, Anthony. (1991): As consequências da modernidade. Tradução de Raul Fiker. São Paulo: Editora UNESP.

HABERMAS, Jürgen. (2010). Pensamento Pós Metafísico. Rio de Janeiro: Pensamento Tempo Brasileiro.

LIPOVETSKY, Gilles. (2004): Os tempos Hipermodernos. Tradução: Mário Vilela. São Paulo: Editora Bacarolla.

LYOTARD, Jean-François. (2009): A condição pós-moderna Tradução: Ricardo Corrêa Barbosa. Rio de Janeiro: José Olympio.

PALMER, Richard. (1969): Hermenêutica. Tradução: Maria Luisa Ribeiro Ferreira. Portugal: Edições 70.

VANDANA SHIVA. (2006). Guerras por água: privatização, poluição e lucro. São Paulo: Radical Livros. 